\title{
EFFECT OF THE STRUCTURE OF COMMERCIAL POLY(ETHYLENE OXIDE-B-PROPYLENE OXIDE) DEMULSIFIER BASES ON THE DEMULSIFICATION OF WATER-IN-CRUDE OIL EMULSIONS: ELUCIDATION OF THE DEMULSIFICATION MECHANISM
}

\author{
João Batista V. S. Ramalho \\ Petrobras Centro de Pesquisas, Av. Horácio Macedo, 950, Cidade Universitária Ilha do Fundão, 21941-915 Rio de Janeiro - RJ, Brasil \\ Fernanda C. Lechuga e Elizabete F. Lucas* \\ Instituto de Macromoléculas Profa. Eloisa Mano, Universidade Federal do Rio de Janeiro, CT, Bl. J, Ilha do Fundão, 21945-970 \\ Rio de Janeiro - RJ, Brasil
}

Recebido em 29/10/09; aceito em 8/4/10; publicado na web em 24/8/10

\begin{abstract}
Water-in-crude oil emulsions are formed during petroleum production and asphaltenes play an important role in their stabilization. Demulsifiers are added to destabilize such emulsions, however the demulsification mechanism is not completely known. In this paper, the performances of commercial poly(ethylene oxide-b-propylene oxide) demulsifiers were studied using synthetic water-in-oil emulsions and model-systems (asphaltenes in organic solvent). No change in the asphaltene aggregate size induced by the demulsifier was observed. The demulsification performance decreased as the asphaltene aggregate size increased, so it can be suggested that the demulsification mechanism is correlated to the voids between the aggregates adsorbed on the water droplets surface.
\end{abstract}

Keywords: poly(ethylene oxide-b-propylene oxide); demulsification mechanism; water-in-crude oil emulsion.

\section{INTRODUCTION}

Normally petroleum is produced along with water containing large amounts of inorganic salts. These two phases are dispersed one into the other and form stable emulsions as they are squeezed through the pores in the reservoir and flow through the production column and lines. The emulsification of these insoluble phases occurs by the shear induced during flow and by the indigenous surfactant species existing in crude oil, which are adsorbed at the water droplet surface and form a physical barrier that prevents the water droplets from coalescing. The water-in-oil emulsion type, i.e. water droplets dispersed in crude oil, is preferably formed because of the amphiphilic characteristic of these natural surfactants is mainly lipophilic.

Water and salts bring serious problems to the refinery processes, such as corrosion, scaling and impeded activity of some catalysts, which are used to crack bigger molecules into smaller ones. ${ }^{1-6}$

Due to the complex composition of crude oils, it is common to characterize each crude oil in terms the four SARA-fractions: saturates (S); aromatics (A); resins (R); asphaltenes (A). ${ }^{7}$ The asphaltenes are defined as the crude oil fraction insoluble in high apolar light n-alkanes, such as n-pentane or n-heptane, and soluble in low polar solvents, such as benzene and toluene. The resins comprise the fraction soluble in $n$-pentane and $n$-heptane but insoluble in propane. The asphaltene macromolecules are generally distinguished by having fused aromatic rings carrying aliphatic chains and rings containing some polar functional group such as sulfide, aldehyde, carbonyl, carboxylic, amine, amide and some metals like nickel, vanadium and iron, which confer polarity and amphiphilic characteristics to these macromolecules. The resins have similar molecular structure to the asphaltenes, but they are smaller, have fewer aromatic rings, functional groups and metals. The asphaltene macromolecules interact with each other by the $\pi$-bond overlap of fused aromatic rings, hydrogen bonding and Lewis acid-base interactions, leading to their aggregation. It is believed that the resins solvate the asphaltene macromolecules and disperse the asphaltenes into smaller aggregates.

*e-mail: elucas@ima.ufrj.br
It has been suggested that the asphaltene aggregates are adsorbed on the water droplet surface and form a rigid interfacial film..$^{8-11}$

Many researchers have shown that asphaltene and resin fractions have a large effect on the stability of water-in-oil emulsions. ${ }^{11-13}$ Sjöblom et al. proved that asphaltenes play a great role in water-in-oil emulsion stability. Later they concluded that the stability is strongly affected by the interaction between asphaltenes and resins. ${ }^{14,15}$ Mingyuan et al. noted that asphaltenes cause water-in-oil emulsions to be much more stable than the resins do and that the emulsion stability is a function of: the aromaticity; the type of functional group existing in the macromolecular structure; and the molecular size of these fractions. ${ }^{16}$ Mohammed et al. also observed that resins do not yield stable water-in-oil emulsions and they affirmed that asphaltenes mainly contribute to the stability of the water-in-oil emulsions. ${ }^{17}$ Førdedal et al. showed that resins alone cannot stabilize water-in-oil emulsions and the ratio of resins to asphaltenes is an important factor determining emulsion stability. ${ }^{18}$ Working with model oil formulated by dissolving different amounts of resins and/or asphaltenes in mixtures of toluene and heptane, MacLean and Kilpatrick correlated the stability of the water-in-oil emulsion with the asphaltene aggregation grade, which is sensitive to the aromaticity of the medium, the ratio of resins to asphaltenes and the polar group concentration. They attributed decreasing water-in oil emulsion stability to the decrease of the asphaltene aggregate size ${ }^{19,20}$ Further works have also correlated the emulsion stability to the asphaltenes aggregation grade. ${ }^{21-25}$ However, none of these researchers quantified the asphaltene aggregate size.

The petroleum industry uses surface-active chemicals to destabilize water-in-crude oil emulsions. These emulsion breakers are known as demulsifiers. Commercial demulsifiers are formulated with one or a mixture of active agents, usually called demulsifier bases, dissolved in organic solvents, such as toluene, xylene, short-chain alcohol, and aromatic naphtha. The most commonly used demulsifier agents are the poly(ethylene oxide-b-propylene oxide) (PEO-b-PPO) copolymer, and their macromolecules exhibit amphiphilic characteristics. The poly(ethylene oxide) (PEO) segment is more hydrophilic and interacts preferably to the water molecule. The poly(propylene oxide) (PPO) segment is more lipophilic and mainly interacts with the organic phase. ${ }^{26-28}$ The common bases used in the formulation 
of the commercial demulsifiers are polyoxyalkylated alkyl-phenolformaldehyde resins and polyoxyalkylated glycols. Other components, such as polyoxyalkylated epoxy resins, polyoxyalkylated amines, polyestereamines and sulfonic acid salts, can be used at lower concentrations. Normally, each crude oil requires the use of a specific demulsifier formulation, due to the difference in the chemical composition of each oil. The suppliers generally use the bottle test to formulate the best commercial demulsifier formulation for a specific crude oil emulsion. The demulsifier dosage added to the emulsion in the field normally varies from 10 to $100 \mathrm{ppm}^{29-31}$

A widely accepted theory explains emulsion stabilization by the Marangoni-Gibbs effect. ${ }^{32}$ When two water droplets approach each other, a surface deformation forms between the droplets and a thin liquid interstitial film remains between them. By capillarity, the liquid film tends to be drained out and some adsorbed surfactant molecules are carried out from the interface. This surfactant loss generates a tension gradient at the interface. Then, a reverse flux is created in order to regenerate the surfactant concentration at the interface and the interstitial film thinning stops. The coalescence between the droplets only will take place with the thinning and the drainage of the interstitial film.

Zaprynova et al. determined that the thinness of the film is significantly affected by the interfacial tension gradient, which results in a reduction in the mobility of the film surface and a decrease in the rate of film thinning. ${ }^{33}$ Mohammed et al. established that the main role of the demulsifier is to enhance the film thinning by suppressing the tension gradient at the interface. ${ }^{34}$ Some works have shown a good correlation between the performance of some commercial demulsifiers and the interfacial tension gradient, with the performance improving as the gradient declines. ${ }^{35,36}$ Nevertheless, Djuve et al. concluded that the reduction of the interfacial tension is one condition, but not alone sufficient for efficient demulsifier action. ${ }^{37}$

Demulsification is a process in which an emulsion is destabilized by the addition of a demulsifier. Some researchers state that the demulsifier replaces the emulsifier at the interface since the interfacial elasticity decreases..$^{38,39}$ Sun et al. concluded that the demulsifier leaves small voids at the interface after occupying the water droplet surface, which keeps out the emulsifiers from the interface.$^{40}$ Ese et $a l$. suggested that the demulsifier disperses the asphaltene aggregates like resins do ${ }^{41}$ as the images from atomic-force microscopy (AFM) of asphaltene films showed an open structure with regions completely uncovered when $100 \mathrm{ppm}$ of demulsifier was added, similar to the effect of resins. ${ }^{42}$ Aske observed a decline in the baseline of near infrared (NIR) spectra when 10-15 ppm of demulsifier was added to North Sea crude oil and he concluded that the demulsifier had dispersed and reduced the asphaltene aggregate size. ${ }^{43}$

The main purpose of this experimental work is to contribute to better elucidation of the destabilization mechanism of water-in-crude oil emulsions by the action of emulsion breakers (demulsifiers). Three commercial poly(ethylene oxide-b-ethylene oxide) copolymers, having different molecular structures (linear, star and branched) and different molecular masses were used. Three different crude oils were used in the experimental studies, along with the asphaltene fractions extracted from them. Real systems (crude oil and commercial demulsifier base) and model systems (demulsifier base and asphaltenes dissolved in solvents) were studied in order to correlate the demulsifier performance and asphaltene particle size.

\section{EXPERIMENTAL}

\section{Materials}

The three Brazilian crude oils were labeled P1, P2 and P3. Table 1 presents some physical and chemical characteristics of the crude oils ${ }^{44}$ that were selected in order to predict their tendency in stabilizing water-in-crude oil emulsions.

Table 1. Physical and chemical characteristics of the three crude oils (labeled $\mathrm{P} 1, \mathrm{P} 2$ and $\mathrm{P} 3)^{44}$

\begin{tabular}{lccc}
\hline Property & \multicolumn{3}{c}{ Crude oil } \\
& P1 & P2 & P3 \\
\hline API density ( $\left.{ }^{\circ} \mathrm{API}\right)$ & 28.3 & 23.9 & 19.0 \\
Viscosity at $25^{\circ} \mathrm{C}(\mathrm{cSt})$ & 39.5 & 64.3 & 96.8 \\
Saturates (w\%) & 58.4 & 47.1 & 40.5 \\
Aromatics (w\%) & 26.2 & 29.3 & 30.8 \\
Resins (w\%) & 14.6 & 22.3 & 26.2 \\
Asphaltenes (w\%) & 0.79 & 1.30 & 2.50 \\
Resins/Asphaltenes & 18.5 & 17.2 & 10.5 \\
Nickel (mg/kg) & 4 & 12 & 20 \\
Vanadium (mg/kg) & 6 & 18 & 29 \\
\hline
\end{tabular}

Three commercial demulsifier bases were used in the experimental studies. All of them were constituted of poly(ethylene oxide-b-propylene oxide) copolymers, but having different molecular structures. The commercial demulsifier bases were supplied by Dow Química do Brasil. The base B1 was synthesized by alkoxylation of monopropylene glycol and the macromolecule had a linear configuration. The base B2 was synthesized by alkoxylation of glycerin and the macromolecule had a star configuration. The base B3 was synthesized by alkoxylation of nonyl-phenol-formaldehyde resin and the macromolecule had a branched configuration.

\section{Methods}

\section{Asphaltene extraction and characterization}

The asphaltenes were extracted from the crude oils by precipitation at room temperature with $40: 1 \mathrm{v} / \mathrm{v}$ of n-heptane to crude oil volumetric ratio, followed by filtration and exhausted washing with n-heptane, based on the preparation method described in IP 143/01. ${ }^{45}$ The asphaltenes were labeled as AP1, AP2 and AP3, respectively to the crude oils.

The asphaltene fractions were characterized regarding to: (a) molar mass, by size exclusion chromatography (SEC), using a Waters gel permeation chromatography system (Waters 600E pump, Waters WISP 717 sample injector and Alltech 2000ES evaporative light scattering detector) and a set of Ultrastyragel columns (7.8 x $300 \mathrm{~mm}, 10^{3}, 500$ and $50 \AA$ ). Distillated tetrahydrofuran (THF) was used as a solvent (at $0.6 \mathrm{~mL} / \mathrm{min}$ ) and polystyrene solutions in THF as calibration standard. Number average molar mass $\left.\left(<M_{n}\right\rangle\right)$ and weight average molar mass $\left(<\mathrm{M}_{\mathrm{w}}>\right)$ were determined. (b) Some heteroatom elements, such as sulfur $(\mathrm{S})$, carbon $(\mathrm{C})$, hydrogen $(\mathrm{H})$, nitrogen $(\mathrm{N})$ and oxygen $(\mathrm{O})$, according to the preparation methods described in ASTM D 1552-03 and ASTM D 5291-02..46,47 (c) Aromatic carbons and saturated, using ${ }^{13} \mathrm{C}$ nuclear magnetic resonance $\left({ }^{13} \mathrm{C} \mathrm{NMR}\right)-\mathrm{Va}-$ rian 400-MR spectrometer, operating at $50.3 \mathrm{MHz}$, room temperature, pulse angle of $90^{\circ}(13.0 \mu \mathrm{s})$, pulse repetitions of $10 \mathrm{~s}$, spectral width of $12.5 \mathrm{KHz}$, acquisition time of $1.5 \mathrm{~s}$ and 24000 scans. The spectra were acquired from $15 \% \mathrm{w} / \mathrm{v}$ of asphaltene solution in deutered chloroform $\left(\mathrm{CDCl}_{3}\right)$ containing $0.05 \mathrm{M}$ of chrome acetyl acetonate as a relaxation agent. The aromatic carbon peaks were integrated in the interval of 100 and $180 \mathrm{ppm}$ and the saturated carbons peaks were integrated from 0 to $70 \mathrm{ppm}$. (d) Aromatic hydrogen, using ${ }^{1} \mathrm{H}$ NMR - Varian 400-MR spectrometer, operating at $200 \mathrm{MHz}$, room temperature, pulse angle of $45^{\circ}(7.0 \mu \mathrm{s})$, pulse repetitions of $1.0 \mathrm{~s}$, spectral width of $3,000 \mathrm{~Hz}$, acquisition time of $1.5 \mathrm{~s}$ and 500 scans. 
The spectra were acquired from the $5 \mathrm{w} / \mathrm{v} \%$ asphaltene solution in $\mathrm{CDCl}_{3}$ and $\mathrm{C}_{2} \mathrm{Cl}_{3}(1: 1 \mathrm{v} / \mathrm{v})$. The aromatic hydrogen peaks were integrated in the interval between 6.4 and $9 \mathrm{ppm}$ and the saturated hydrogen peaks integrated between 2 and $6 \mathrm{ppm}$.

\section{Determination of asphaltene particle size}

The size of the asphaltene particles was determined by using a Zetasizer Nano Series particle size analyzer, from Malvern Instruments Ltd. ${ }^{48}$ The extracted asphaltene fractions were studied in model systems constituted of toluene and n-heptane solvent mixtures at different concentrations. To formulate these concentrations, first $0.25 \% \mathrm{w} / \mathrm{v}$ of each asphaltene was dissolved in toluene (T). After that, the organic phase was built up by adding $0.025 \% \mathrm{w} / \mathrm{v}$ of the dissolved asphaltenes to toluene and to the volumetric mixtures of toluene and n-heptane $(\mathrm{H})$ in proportions of 4:3, 3:4, 2:5 and 1:6.

The effect of the commercial demulsifier bases on the asphaltene aggregation was also quantified. $0.0050 \% \mathrm{w} / \mathrm{v}$ of the asphaltenes was added to the volumetric mixtures of toluene and n-heptane in proportions of 3:4 and 2:5. Each demulsifier base was added at the dosage of $50 \mathrm{ppm}$ of active-material.

Characterization of the poly(ethylene oxide)-poly(propylene oxide) block copolymers

Each commercial demulsifier base was characterized in relation to: (a) molar mass by SEC, using the same equipment and conditions described in the preceding item; (b) the percentage of ethylene oxide, by ${ }^{13} \mathrm{C}$ NMR, using a Varian 400-MR spectrometer, operating at 75.4 $\mathrm{KHz}$. The spectra were acquired from the $40 \mathrm{w} / \mathrm{v} \%$ demulsifier base solution in $\mathrm{CDCl}_{3}$. The carbon peaks were in the intervals: $16-20 \mathrm{ppm}$ and $69-76 \mathrm{ppm}^{49}$

\section{Demulsification tests}

The demulsification tests were carried out using a synthetic waterin-oil emulsion. Two different organic phases were used: crude oil and asphaltenes in an organic solvent.

The water-in-oil emulsions were synthesized from the three crude oils to have $30.0 \mathrm{v} / \mathrm{v} \%$ of water content. The aqueous phase was a $50 \mathrm{~g} / \mathrm{L} \mathrm{NaCl}$ solution. One liter of each emulsion was prepared by shearing the fluids in a Polytron PT 3100 homogenizer, at $8000 \mathrm{rpm}$ for 3 min. ${ }^{50}$ The emulsion demulsification was evaluated by bottle tests. $100 \mathrm{~mL}$ of emulsion was previously heated at the assay temperature before adding $100 \mu \mathrm{L}$ of $50 \mathrm{w} / \mathrm{v} \%$ demulsifier base solution in toluene, which corresponds to $\sim 50 \mathrm{ppm}$ of active-material of the demulsifier base (B1, B2 or B3) added to the emulsion. Each demulsifier base solution was prepared by dissolving the polymer in toluene at the concentration of $50 \mathrm{w} / \mathrm{w} \%$. The assay temperature was that at which the oil had a viscosity of $16 \mathrm{cSt}$. Such viscosity is used as standard for measurements in the Petroleum Industry. Using a DV-III Ultra programmable rheometer with spindle SC-18 (Brookfield, Inc.), the $16 \mathrm{cSt}$ viscosity was observed at 40,64 and $97{ }^{\circ} \mathrm{C}$, respectively, for P1, P2 and P3. After preparing each emulsion, a Matersizer 2000 particle size analyzer (Malvern Instruments Ltd.) was used to quantify the water droplet size. The separated water volume was quantified during $40 \mathrm{~min}$ at every $5 \mathrm{~min}$ and the demulsification performance was quantified by calculating the water separation index (WSI):

$$
\operatorname{WSI}(\%)=\frac{\sum(\mathrm{SW} / 100)^{2}}{\mathrm{~N}}
$$

where $\mathrm{SW}$ is the separated water (\%) and $\mathrm{N}$ is the number of measures of the separated water.

For the tests in which the oil phase consisted of asphaltenes in organic solvent, we used $0.025 \mathrm{w} / \mathrm{v} \%$ of asphaltenes in toluene and mixtures of toluene and n-heptane in volumetric proportions of $4: 3$, $3: 4,2: 5$ and 1:6. The aqueous phase remained a $50 \mathrm{~g} / \mathrm{L} \mathrm{NaCl}$ solution. The demulsification performance was evaluated with the model emulsions prepared under the same conditions described before, but they were sheared at $8,000 \mathrm{rpm}$ for $1 \mathrm{~min}$. The separated water was measured during of $40 \mathrm{~min}$ at room temperature after adding $50 \mathrm{ppm}$ of active-material of demulsifier base B1 to the emulsion.

\section{RESULTS AND DISCUSSION}

\section{Commercial demulsifier base characterization}

Table 2 presents the chemical characterization of these commercial bases. The results show that the demulsifier bases have very similar ethylene oxide (EO) content ( $30 \mathrm{~mol} \%)$. The average molar masses of the star and branched structures $(4,260$ and 3,630 g/mol, respectively) are almost twice those of the linear one $(2,220 \mathrm{~g} / \mathrm{mol})$. As expected, the polydispersity values are quite low since the products are industrially prepared by ionic polymerization.

Table 2. Demulsifier base chemical characterization

\begin{tabular}{lccc}
\hline Property & \multicolumn{3}{c}{ Demulsifier base } \\
\hline EO $(\mathrm{mol} \%) *$ & 34 & B2 & B3 \\
$<\mathrm{M}_{\mathrm{n}}>(\mathrm{g} / \mathrm{mol}) * *$ & 2,220 & 4,260 & 31 \\
$\left\langle\mathrm{M}_{\mathrm{w}}\right\rangle(\mathrm{g} / \mathrm{mol}) * *$ & 2,340 & 4,420 & 4,630 \\
\hline
\end{tabular}

*Determined by ${ }^{13} \mathrm{C}$ NMR. **Determined by SEC

\section{Asphaltene characterization}

The chemical characteristics of the three asphaltenes (AP1, AP2 and AP3) were determined in order to predict their tendencies to form aggregates and to stabilize water-in-oil emulsions. Table 3 shows the results of weighted average molar mass $\left(\left\langle\mathrm{M}_{\mathrm{w}}\right\rangle\right)$ and the content of carbon, hydrogen, oxygen, nitrogen, sulfur, nickel, vanadium, heteroatoms, aromatic carbon and aromatic hydrogen. The molar mass found for AP1, AP2 and AP3 were, respectively, 4,430; 5,350 and 6,400 g/ mol. The molar mass for AP3 is about $50 \%$ higher than that for AP1. In fact, such values are some higher than that suggested by the recent literature ${ }^{51}$ and, in fact, could already express the aggregate tendency of asphaltenes. The carbon and hydrogen contents were quite similar for the three asphaltene fractions: 85 and $8.5 \mathrm{w} / \mathrm{w} \%$, respectively. The nitrogen, sulfur, nickel and vanadium concentrations followed the same tendency as molar mass, i.e., they increased from AP1 to AP3. The oxygen, aromatic carbon and aromatic hydrogen concentrations increased in the following order: AP2 $<$ AP3 $<$ AP1. These results show the asphaltenes had different characteristics.

\section{Demulsifier base performance for water-in-crude oil emulsions}

The demulsification performances of the three commercial demulsifier bases were evaluated to study the effect of the molecular structure on the demulsification mechanism. Table 4 summarizes the assay conditions. It shows that the emulsions were synthesized having similar average water droplet diameters $(\sim 10 \mu \mathrm{m})$ and that the demulsification took place at the temperature at which the oil continuous phase presented similar viscosity values $(\sim 16 \mathrm{cSt})$.

The results obtained for the demulsifier base performances, for demulsification of the water-in-crude oil emulsions prepared from the three different crude oils (P1, P2 and P3). Showed that the best performances were obtained from the systems prepared using P2 crude oil ( $80 \%$ of separated water in about $20 \mathrm{~min}$ ), followed by the 
Table 3. Asphaltene chemical characterization

\begin{tabular}{lccc}
\hline \multirow{2}{*}{ Property } & \multicolumn{3}{c}{ Asphaltenes } \\
\hline$<\mathrm{Mw}>(\mathrm{g} / \mathrm{mol})^{*}$ & 4,430 & 5,350 & 6,400 \\
Carbon (w/w \%) & 85.4 & 86.4 & 85.3 \\
Hydrogen (w/w \%) & 8.70 & 8.50 & 8.20 \\
Oxygen (w/w \%) & 3.53 & 2.17 & 3.43 \\
Nitrogen (w/w \%) & 1.50 & 1.70 & 1.70 \\
Sulfur (w/w \%) & 0.87 & 1.23 & 1.37 \\
Nickel (mg/kg) & 3 & 5 & 8 \\
Vanadium (mg/kg) & 10 & 12 & 16 \\
Heteroatoms (w/w \%) & 5.90 & 5.10 & 6.50 \\
Aromatic carbon (mol \%)** & 54.3 & 40.4 & 49.0 \\
Aromatic hydrogen $(\mathrm{mol} \%)^{* * *}$ & 8.40 & 7.30 & 7.81 \\
\hline
\end{tabular}

*Determined by SEC. **Determined by ${ }^{13} \mathrm{C}$ NMR. ***Determined by ${ }^{1} \mathrm{H}$ NMR

Table 4. Crude oil demulsification assay conditions

\begin{tabular}{lccc}
\hline Parameter & \multicolumn{3}{c}{ Crude oil } \\
\hline Water content $(\mathrm{v} / \mathrm{v} \%)$ & P1 & P2 & P3 \\
Water droplet mean size $(\mu \mathrm{m})$ & 30.0 & 30.0 & 30.0 \\
Separation temperature $-\mathrm{T}\left({ }^{\circ} \mathrm{C}\right)$ & 10.90 & 9.51 & 9.78 \\
Crude oil viscosity at T $(\mathrm{cSt})$ & 40.0 & 64.0 & 97.0 \\
Demulsifier active-material $(\mathrm{ppm})$ & 15.7 & 16.1 & 16.4 \\
\hline
\end{tabular}

P1 emulsion system (45-70\% of separated water in about $20 \mathrm{~min}$ ). The worst performances for the three different demulsifier bases were observed for the P3 crude oil system (5-35\% of separated water in about $20 \mathrm{~min}$ ). The performances of the three demulsifier bases were quite similar when used to separate the $\mathrm{P} 2$ crude oil emulsions: more than $90 \%$ separated water. For the P3 crude oil emulsions, the performances were quite different: 10, 33 and $50 \%$ for B1, B2 and $\mathrm{B} 3$, respectively.

By analyzing only the crude oil characterization data (Table 1) it could be suggested that crude oil P1 $\left(28.3^{\circ} \mathrm{API}\right)$ should have the lowest tendency to form stable water-in-crude oil emulsions than the crude oil P2 (23.9 API) and crude oil P3 (19.0 $\left.{ }^{\circ} \mathrm{API}\right)$, respectively, since crude oil $\mathrm{P} 1$ has lower asphaltene content, higher ratio of resins to asphaltenes and the lower metal content $(\mathrm{Ni}, \mathrm{V})$ than the other two crude oils. Likewise, crude oil P3 should have the highest tendency to form more stable emulsions, since it is the most viscous crude oil, has the highest asphaltene content, lowest ratio of resins to asphaltenes and highest metal content $(\mathrm{Ni}, \mathrm{V})$. In fact, the demulsification performance of the commercial demulsifier bases B1, B2 and B3 in the destabilization of the water-in-crude oil emulsions indicated that crude oil P3 produced the most stable emulsions. Nevertheless, crude oil P1 formed more stable emulsion than that prepared from crude oil P2, both having the same viscosity $(\sim 16 \mathrm{cSt})$.

On the other hand, the asphaltene chemical characterization (Table 3) showed that asphaltenes from crude oil P1 (AP1) had higher aromatic carbon, hydrogen and heteroatom $(\mathrm{O}, \mathrm{N}, \mathrm{S})$ content than the asphaltenes from crude oil P2 (AP2). These analytical results suggest that the asphaltene macromolecules from crude oil P1 contain more aromatic rings and functional groups in their structure than the asphaltene macromolecules from crude oil $\mathrm{P} 2$, which may contribute to higher polarity to the asphaltene macromolecules from crude oil P1. They also suggest that asphaltene macromolecules from the crude oil P1 interact chemically with each other more intensely than do the asphaltene macromolecules from crude oil P2 and produce larger asphaltene aggregates and more rigid asphaltene interfacial films, which yield more stable water-in-crude oil emulsions for crude oil P1 than for crude oil P2, at the same organic phase viscosity. Although the asphaltenes from crude oil P3 (AP3) have lower aromatic carbon and hydrogen content than the asphaltenes from crude oil P1 (AP1), the asphaltene macromolecules from crude oil P3 have the highest heteroatom $(\mathrm{O}, \mathrm{N}, \mathrm{S})$ content, which contributes to form larger and more cohesive asphaltene aggregates for AP1 and AP2, due to the higher intermolecular interaction forces induced by the functional groups. In fact, crude oil P3 rendered a more stable water-in-oil emulsion than crude oils P1 and P2, since its emulsion exhibited the lowest water separation index (WSI) values. To summarize the results observed for demulsifier performance in water-in-crude oil emulsions, the stability of water-in-oil emulsions exhibits the following order: P3 > P1 > P2

\section{Asphaltenes particle size as a function of solvent aromaticity}

The asphaltenes were added to organic phases with different aromaticity degrees to produce aggregates with different sizes. Figure 1 shows the mean asphaltene particle sizes and size distribution percentage for the three different asphaltenes in model solvents (toluene and n-heptane, T:H, at different compositions). The results were quite similar for the three model systems prepared using asphaltenes AP1, AP2 and AP3. At $0.025 \mathrm{wt} \%$ of asphaltenes in toluene, no particles were observed using the Zeta Sizer Nano Series analyzer. That was expected, since toluene is a good asphaltene solvent and there is no tendency to aggregation at low concentration. ${ }^{52}$ When the moiety became more polar ( $\mathrm{T}: \mathrm{H}=4: 3$ and 3:4), it was possible to observe particles around 10 and $20 \mathrm{~nm}$, respectively.

Asphaltene aggregates (around 2,000 nm) could be observed when $0.025 \mathrm{wt} \%$ of asphaltenes were in contact with toluene: $n$-heptane at proportions of 2:5 and 1:6. The asphaltene particles size increased as

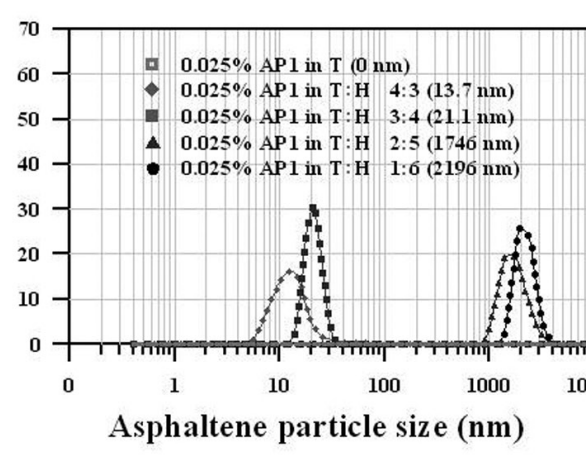

(a)

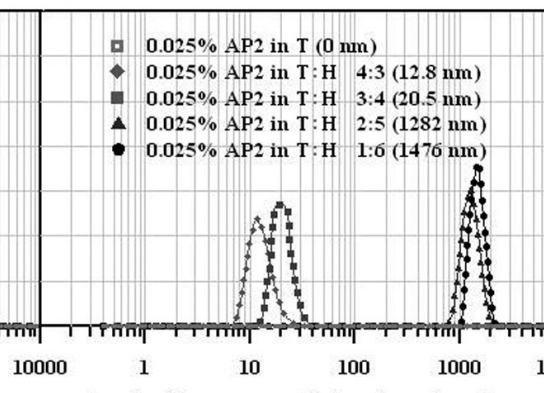

Asphaltene particle size (nm)

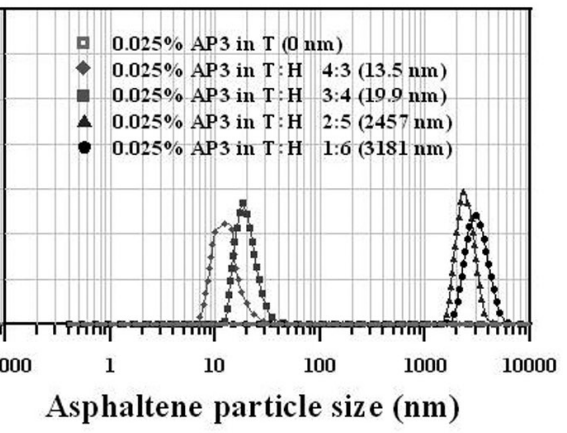

(c)

Figure 1. Asphaltene aggregate size as a function of the aromaticity of the medium for (a) asphaltenes from crude oil 1 (AP1), (b) asphaltenes from crude oil 2 (AP2) and (c) asphaltenes from crude oil 3 (AP3) 


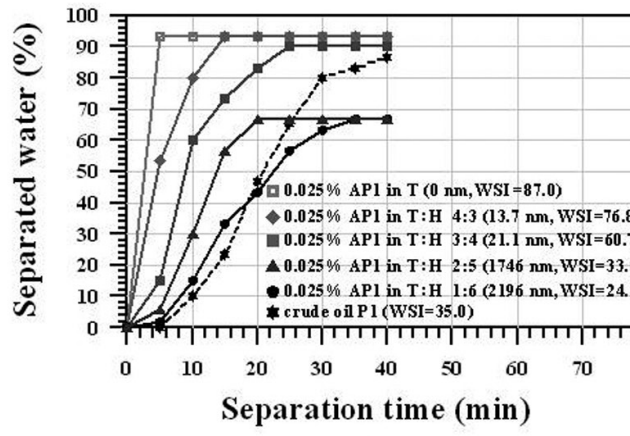

(a)

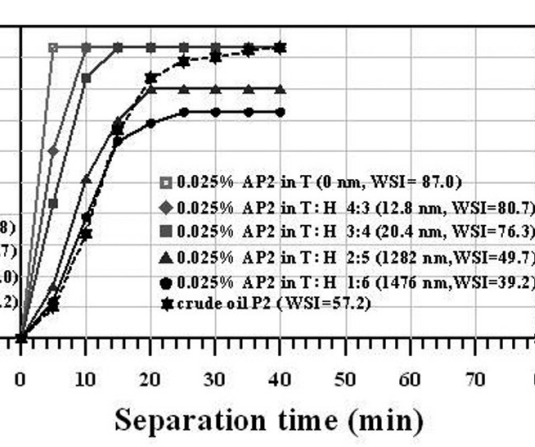

(b)

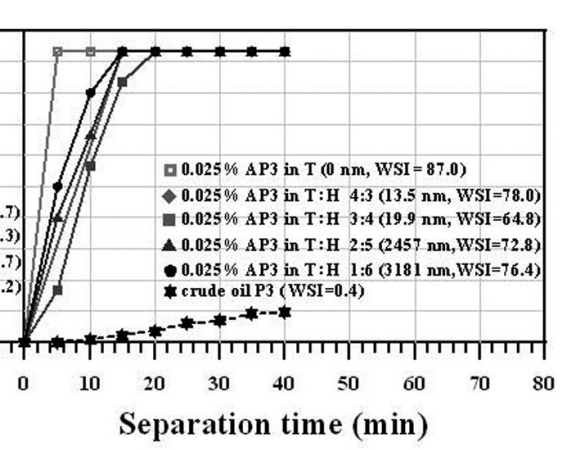

(c)

Figure 2. Demulsification performance as a function of asphaltene aggregate size (50 ppm of B1)

the n-heptane content in the solvent mixture increased and was independent of the type of asphaltene used (AP1, AP2 or AP3). The particle size increase was much more pronounced when the solvent mixture composition was changed from $\mathrm{T}: \mathrm{H}=3: 4$ to $\mathrm{T}: \mathrm{H}=2: 5$.

So, by analyzing the asphaltene aggregate size (Figure 1), induced by the addition of $n$-heptane to the asphaltene in toluene dispersion (at a proportion of $\mathrm{T}: \mathrm{H}=2: 5$ and 1:6), it is observed the same order as that for emulsion stability in Figure 1, that is, the asphaltene aggregate size order was P3 $>$ P1 $>$ P2 . Figure 1 also shows that the asphaltene macromolecules aggregation degree depends on the aromaticity of the moiety. Decreasing aromaticity causes the aggregate size to increase. This means, that in fact, the aggregate size depends on the solvent's capability to solvate and to disperse the asphaltene macromolecules. ${ }^{19,20}$ No asphaltene particles were detected by analyzing the system containing only asphaltenes in toluene.

Focusing on the performance differences of the demulsifier bases, it is observed that for crude oil P1 the star demulsifier base B2 performed best, followed by the linear demulsifier base B1, and finally the branched demulsifier base B3 (B2WSI > B1WSI > B3WSI). However, for crude oil $\mathrm{P} 2$, the performance of base B1 was similar to that of base B2, and base B3 performed worst (B1WSI $=\mathrm{B} 2 \mathrm{~W}$ SI $>$ B3WSI). Although the three commercial bases presented very poor performance in demulsification of the emulsion prepared with crude oil P3, the performance order was: B3WSI > B2WSI > B1WSI. So, no correlation was found between the molecular architecture (linear, star and branched) of the commercial demulsifier bases and its demulsification performance on the crude oil emulsions. These results suggest that the demulsifier macromolecule may be chemically interacting with some crude oil component, which causes a decreasing in the demulsification action of the surfactant.

\section{Influence of asphaltene aggregate size on demulsification performance}

The influence of the asphaltene aggregate size on the demulsification process was investigated using model water-in-oil emulsions: $0.025 \mathrm{wt} \%$ of asphaltenes in solvent mixture (T:H at different compositions). Figures $2 \mathrm{a}, 2 \mathrm{~b}$ and $2 \mathrm{c}$ show the demulsification performances of B1 (at $50 \mathrm{ppm}$ ) added to the model systems prepared with P1, P2 and $\mathrm{P} 3$ crude oil, respectively. For comparison, Figure 2 also shows the $\mathrm{B} 1$ performance in water-in-crude oil emulsions. It is clear that the performance was better when testing the model systems, except for the P2 system, in which the performance for crude oil was better than that for the model system having aggregate sizes higher than $1,000 \mathrm{~nm}$.

An analysis of the effect of base B1 on the model systems (asphaltenes in toluene and n-heptane at several concentrations) showed that the asphaltenes are indeed able to stabilize water-in-oil emulsions. Figure 2 shows different demulsification processes, induced by base B1 addition, for each emulsion that was synthesized with different asphaltene kinds and aggregate. These experimental results also confirm that the asphaltene aggregate size plays an important role in the demulsification mechanism. Furthermore, the demulsification process was much faster for the model system, which can be related to the viscosity differences and/or some kind of interaction between the surfactant and crude oil components, as supposed at the end of the preceding paragraph.

\section{Effect of the demulsifier bases on asphaltene aggregation}

The effect of the commercial demulsifier bases on the asphaltene aggregation was quantified in order to investigate whether the demulsifier bases change the asphaltene aggregate size like the resins do. ${ }^{41,43}$ It was measured the asphaltene particle sizes and their size distribution percentages for the model systems prepared with 0.0050 wt $\%$ of asphaltenes in $\mathrm{T}: \mathrm{H}=3: 4$ and 2:5. The two solvent mixture compositions were selected based on the significant difference in particle size observed in Figure 1. In all cases, B1, B2 and B3 demulsifier bases were added at $50 \mathrm{ppm}$. No significant change in particle size was observed after addition of the demulsifier, independently of the molecular structure (linear, star or branched).

Since it was verified that the asphaltene aggregate size influenced the demulsification process, some experiments were performed adding demulsifier bases in asphaltene model systems containing smaller $(\sim 10 \mathrm{~nm})$ and bigger $(\sim 1,000 \mathrm{~nm})$ asphaltene particle sizes, respectively T:H solvent content of 3:4 and 2:5. No changes in asphaltenes aggregate size were observed when the demulsifier was added, for both small and large particles sizes. This means that the polyoxyalkylated demulsifier bases used in these experimental studies were not able to disperse the asphaltenes as well as resins do. ${ }^{19,20}$

Figure 3 shows the demulsification performance as a function of particle size. The results were gotten from the measures carried out for the synthetic emulsions prepared with asphaltenes extracted from crude oil P1, crude oil P2 and crude oil P3. It is observed a clear decrease in the demulsification performance with increasing asphaltene particle size (Figure 3), before the asphaltene precipitation point. The fact there was no change in the asphaltene particle size when the demulsifier was added to the dispersions suggests that the asphaltene aggregates leave voids between macromolecules when they are adsorbed at the water droplet interface and the demulsifier molecules reach the water droplet interface through those voids and are also adsorbed. For larger asphaltene aggregates, there are fewer voids at the water droplet interface, making it harder for the demulsifier molecules to be adsorbed at the interface, which impairs the 


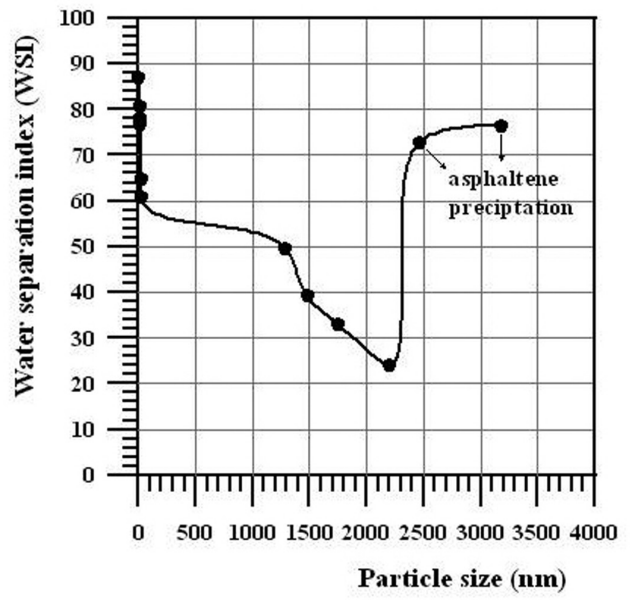

Figure 3. Demulsification performance as a function of asphaltene aggregate size

whole demulsification process. More voids are available with smaller asphaltene aggregate than for larger ones. The emulsion stabilized by the asphaltenes from crude oil P3 (AP3) had its demulsification performance increased when the asphaltenes aggregates size reached mean sizes of 2,500 and 3,100 $\mathrm{nm}$ (Figure 3), because such aggregates are too large to be adsorbed at the interface. Under these two conditions asphaltene precipitation was also observed.

Even though, it is possible that other components within the oil sample may influence the effectiveness of the demulsifier, from experimental results obtained in this work, it is suggested a better understanding of the demulsification mechanism of water-in-crude oil emulsions. The asphaltene aggregates are adsorbed at the water droplet interface and form a barrier that prevents the water droplets from coalescing. Voids are between adjacent asphaltene particles and the demulsifiers added to the system penetrate through the voids and occupy the vacancies at the surface. Asphaltenes presenting high intermolecular interaction forces form large aggregates and a few voids are available, which impairs the penetration of the demulsifier. The more hydrophilic part of the demulsifier molecule strongly interacts with the water molecules and annuls the interaction between the asphaltene aggregates and the water molecules. At this point, the asphaltene aggregates start moving away from the water droplet surface and more demulsifier goes gradually to the surface. The Marangoni-Gibbs effects are suppressed allowing the water droplets to coalesce.

\section{CONCLUSIONS}

This study confirmed that asphaltenes in crude oil play an important role in the stabilization of the water-in-crude-oil emulsions. The demulsification mechanism depends on the aggregation degree of the asphaltene macromolecules in the crude oil, besides the asphaltene content and the crude oil viscosity. The asphaltene aggregate size depends on the intensity of the intermolecular interaction forces: asphaltene macromolecules with higher interactive forces tend to form larger aggregates. However, the aromaticity of the moiety also influences the asphaltene aggregation degree, since the highly aromatic moiety can suppress the asphaltene macromolecules' interactions, reducing the asphaltene aggregate size. The demulsifiers based on poly(ethylene oxide-b-propylene oxide) do not change the asphaltene aggregation degree by peptizing the asphaltene macromolecule as well as resins do. There is no evidence of correlation between the molecular configuration (linear, star and branched) of the demulsifiers based on poly(ethylene oxide-b-propylene oxide) and their performance in the crude oil demulsification process. It is likely that the demulsifier macromolecule interacts differently with some crude oil components, which cause differences in the demulsification performance. Demulsification mechanism could be correlated to the voids left between the asphaltene aggregates adsorbed on the water droplet surface: small asphaltene aggregates generate more voids, making it easier for the demulsifier macromolecule to be adsorbed on the water droplet surface, thus facilitating the demulsification; similarly, larger asphaltene aggregates prevent the demulsifier adsorption at the interface.

\section{SUPPLEMENTARY MATERIAL}

The following material is available for free at PDF format at http://quimicanova.sbq.org.br: Figure 1S showing the demulsifier base performance on demulsification of crude oil (a) P1, (b) P2 and (c) P3; Figure 2S showing the asphaltene aggregate size of (a) AP1, (b) AP2 and (c) AP3 with and without the addition of $50 \mathrm{ppm}$ of active demulsifier base material, at different toluene/heptane ratios; Figure $3 \mathrm{~S}$ illustrating in simplified form the voids between the asphaltene aggregates adsorbed at the water droplet surface; and Figure $4 \mathrm{~S}$ exhibiting a schematic illustration of the demulsification mechanism of the water-in-oil emulsions proposed in this work.

\section{ACKNOWLEDGMENT}

The authors thank FINEP, CNPq, CAPES, FAPERJ, the National Petroleum Agency (ANP) and PETROBRAS for financial support.

\section{REFERENCES}

1. Strassner, J. E.; J. Pet. Technol. 1968, 20, 301.

2. Kimbler, O. K.; Reed, R. L.; Silberberg, I. H.; Soc. Pet. Eng. J. 1966, 6, 153.

3. Eley, D. D.; Hey, M. J.; Symonds, J. D.; Willison, J. H. M.; J. Colloid Interface Sci. 1976, 54, 462.

4. Johansen, E. J.; Skjarvo, I. M.; Lund, T.; Sjöblom, J.; Soderland, H.; Bostrom, G.; Colloids Surf. 1989, 34, 353.

5. Schramm, L. L. In Petroleum emulsion: basic principles, in Emulsions: fundamentals and applications in the petroleum industry; Schramm, L. L, ed.; American Chemical Society: Washington, D. C., 1992, cap. 1.

6. Sjöblom, J.; Aske, N.; Auflem, I. H.; Brandal, O.; Havre, T. E.; Saether, O.; Westvik, A.; Johnsen, E. E.; Kallevik, H.; Adv. Colloid Interface Sci. 2003, 100-102, 399

7. Sjöblom, J.; Hemmingsen, P.; Kallevick, H. In Asphaltenes, heavy oils, and petroleomics; Mullins, O. C.; Sheu, E. Y.; Hammani, A.; Marshall, A. G., eds.; Springer: New York, 2007, cap. 21.

8. Kilpatrick, P. K.; Spiecker, P. M. In Encyclopedic Handbook of Emulsion Technology; Sjöblom, J., ed; Marcel Dekker: New York, 2001, cap. 30.

9. Aske, N.; Kallevik, H.; Sjöblom, J.; Energy Fuels 2001, 15, 1304.

10. Andersen, S. I.; Speight, J. G.; Pet. Sci. Technol. 2001, 19, 1.

11. Sheu, E. Y.; Energy Fuels 2002, 16, 74.

12. Neumann, H. J.; Paczynska-Lahme, B.; Prog. Colloid Polym. Sci. 1988, $77,123$.

13. Sjöblom, J.; Urdahl, O.; Holland, H.; Christy, A. A.; Johansen, E. J.; Prog. Colloid Polym. Sci. 1990, 82, 131.

14. Sjöblom, J.; Söderlund, H.; Lindblad, S.; Johansen, E. J.; Skärvö, I. M.; Colloid Polym. Sci. 1990, 268, 389.

15. Sjöblom, J.; Urdahl, O.; Borve, K. G. N.; Mingyuan, L.; Saeten, J. O.; Christy, A. A.; Gu, T.; Adv. Colloid Interface Sci. 1992, 41, 241.

16. Mingyuan, L.; Christy, A. A.; Sjöblom, J. In Emulsions: a fundamental and a practical approach; Sjöblom, J., ed.; Kluwer Academic Publisher: Netherlands, 1992, cap. 11. 
17. Mohammed, R. A.; Bailey, A. I.; Luckham, P. F.; Taylor, S. E.; Colloids Surf., A 1993, 80, 237.

18. Føderdal, H.; Schildberg, Y.; Sjöblom, J.; Volle, J. L.; Colloids Surf., A 1996, 106, 33.

19. MacLean, J. D.; Kilpatrick, P. K.; J. Colloid Interface Sci. 1997, 189, 242.

20. MacLean, J. D.; Kilpatrick, P. K.; J. Colloid Interface Sci. 1997, 196, 23.

21. Schorling, P.-C.; Kessel, D. G.; Rahimian, I.; Colloids Surf., A 1999, 152,95 .

22. Spiecker, P. M.; Gawrys, K. L.; Trail, C. B.; Kilpatrick, P. K.; Colloids Surf., A 2003, 220, 1309.

23. Fingas, M.; Fieldhouse, B.; Mar. Pollut. Bull. 2003, 47, 369.

24. Havre, T. E.; Sjöblom, J.; Colloids Surf., A 2003, 228, 131.

25. Xia, L.; Lu, S.; Cao, G.; J. Colloid Interface Sci. 2004, 271, 504.

26. Xu, Y.; Wu, J.; Dabros, T.; Hamza, H.; Energy Fuels 2005, 19, 916.

27. Kang, W.; Jing, G.; Zhang, H.; Li; M.; Wu, Z.; Colloids Surf., A 2006, 272, 27.

28. Rondón, M.; Bouriat, P.; Lachaise, J.; Energy Fuels 2006, 20, 1600.

29. Spencer, E. T.; Chem. Ind. 1992, $20,770$.

30. Mohammed, R. A.; Bailey, A. I.; Luckham, P. F.; Taylor, S. E.; Colloids Surf., A 1994, 83, 261.

31. Bolívar, C. R. A.; Contreras, P.; Méndes, R.; Tovar, J. G.; Visión Tecnológica 2000, 7, 167.

32. Wasan, D. T. In ref. 16, cap. 19.

33. Zaprynova, Z.; Malhota, A. K.; Aderangi, N.; Wasan, D. T.; Int. J. Multiphase Flow 1983, 9, 105.

34. Mohammed, R. A.; Baily, A. I.; Luckham, P. F.; Taylor, S. E.; Colloids Surf., A 1994, 83, 261.

35. Kim, H. Y.; Wasan, D. T.; Breen, P. J.; Colloids Surf,. A 1995, 95, 235.

36. Kim, H. Y.; Wasan, D. T.; Ind. Eng. Chem. Res. 1996, 35, 1141.

37. Djuve, J.; Yang, X.; Fjellanger, I. J.; Sjöblom, J.; Pelizzetty, E.; Colloid Polym. Sci. 2001, 279, 232.
38. Wang, Y.; Zhang, L.; Sun, T.; Zhao, S.; Yu, J.; J. Colloid Interface Sci. 2004, 270, 163.

39. Kang, W.; Jing, G.; Zhang, H.; Li, M.; Wu, Z.; Colloids Surf., A 2006, 272, 27.

40. Sun, T.; Zhang, L.; Wang, Y.; Zhao, S.; Peng, B.; Li, M.; Yu, J.; J. Colloid Interface Sci. 2002, 255, 241.

41. Ese, M.-H.; Galet, L.; Clausse, D.; Sjöblom, J.; J. Colloid Interface Sci. 1999, 220, 293.

42. Sjöblom, J.; Johnsen, E. E.; Westvik, A.; Ese, M.-E.; Djuve, J.; Auflem, I. H.; Kallevik, H. In ref. 8, cap. 25.

43. Aske, N.; PhD Thesis, Norwegian University of Science and Technology, Trondheim, 2002.

44. PETROBRAS - Research Center, private Database.

45. Standard test method for determination of asphaltenes (heptane insoluble) in crude petroleum and petroleum products, Institute of Petroleum, London, IP 143/01, 2001.

46. Standard test method for sulfur in petroleum products (high-temperature method), American Standard Test Methods, West Conshohocken, ASTM D 1552-03.

47. Standard test methods for Instrumental Determination of carbon, hydrogen and nitrogen in petroleum products and lubricants, American Standard Test Methods, West Conshohocken, ASTM D 5291-02.

48. Ramalho, J. B. V. S.; Oliveira, M. C. K.; Boletim Técnico da PETROBRAS 1999, 42, 72.

49. Mansur, C. R. E.; Lucas, E. F.; Pacheco, C. R. N.; González, G.; Quim. Nova 2001, 24, 47.

50. Mansur, C. R. E.; Barboza, S. P.; González, G.; Lucas, E. F.; J. Colloid Interface Sci. 2004, 271, 232.

51. Mullins, O. C.; Martinez-Haya, B.; Marshall, A. G.; Energy Fuels 2008, $22,1765$.

52. Middea, A.; Monte, M. B. M.; Lucas, E. F.; Chem. Chem. Technol. 2008, 2, 91 . 


\section{EFFECT OF THE STRUCTURE OF COMMERCIAL POLY(ETHYLENE OXIDE-B-PROPYLENE OXIDE) DEMULSIFIER BASES ON THE DEMULSIFICATION OF WATER-IN-CRUDE OIL EMULSIONS: ELUCIDATION OF THE DEMULSIFICATION MECHANISM}

\section{João Batista V. S. Ramalho}

Petrobras Centro de Pesquisas, Av. Horácio Macedo, 950, Cidade Universitária Ilha do Fundão, 21941-915 Rio de Janeiro - RJ, Brasil Fernanda C. Lechuga e Elizabete F. Lucas*

Instituto de Macromoléculas Profa. Eloisa Mano, Universidade Federal do Rio de Janeiro, CT, Bl. J, Ilha do Fundão, 21945-970 Rio de Janeiro - RJ, Brasil

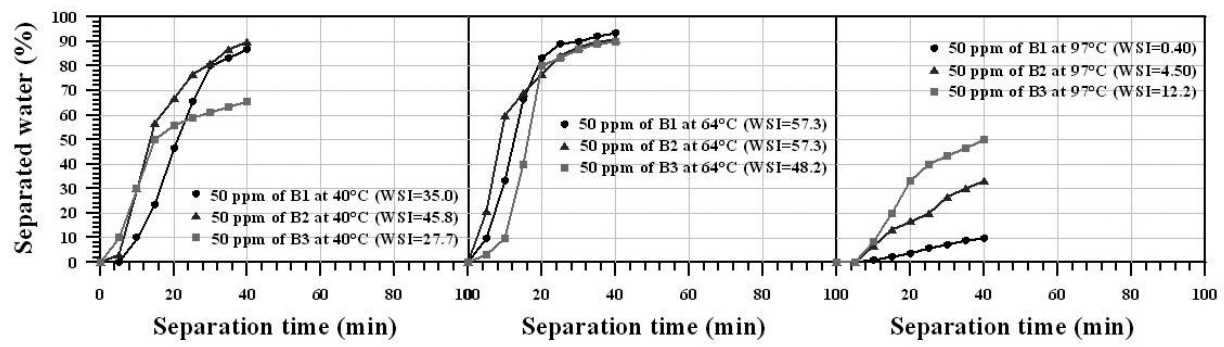

(a)

(b)

(c)

Figure 1S. Demulsifier base performance on demulsification of crude oil (a) $P 1,(b) P 2$ and (c) P3
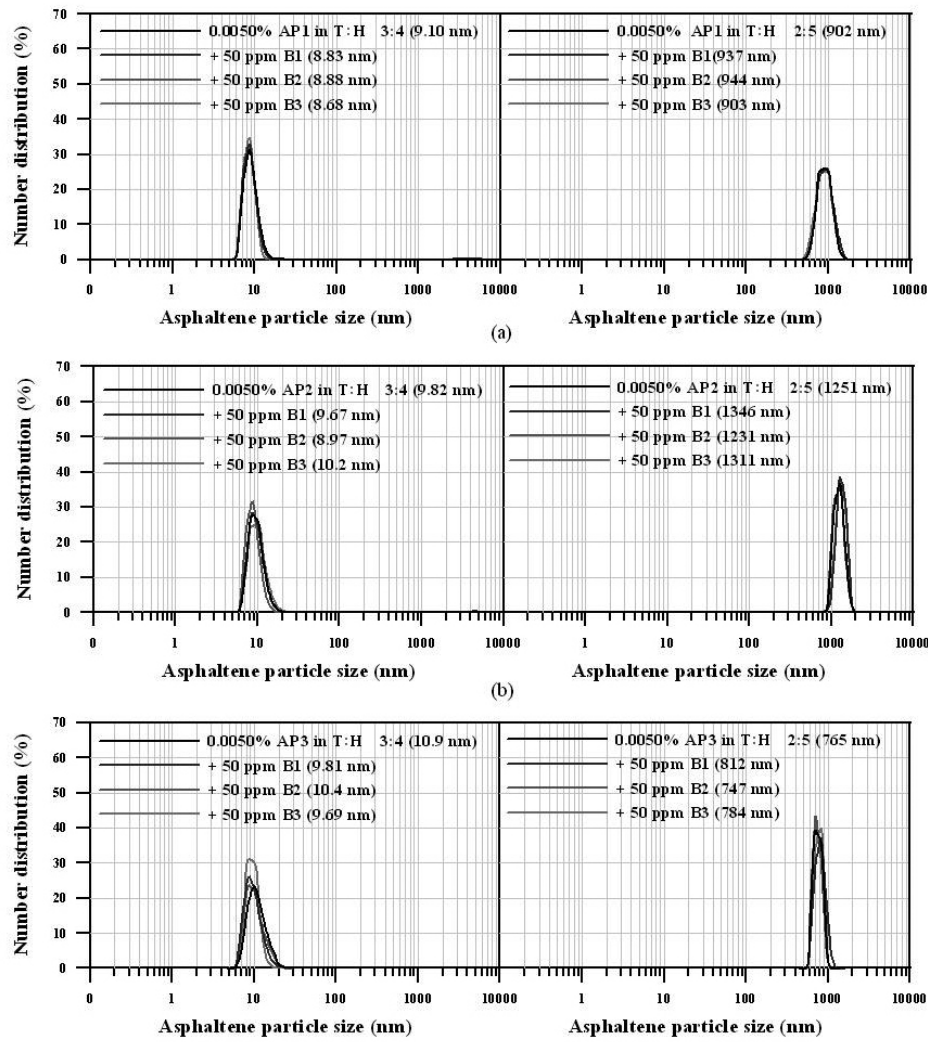

(c)

Figure 2S. Asphaltene aggregate size of (a) AP1, (b) AP2 and (c) AP3 with and without the addition of 50 ppm of active demulsifier base material, at different toluene/heptane ratios

*e-mail: elucas@ima.ufrj.br 


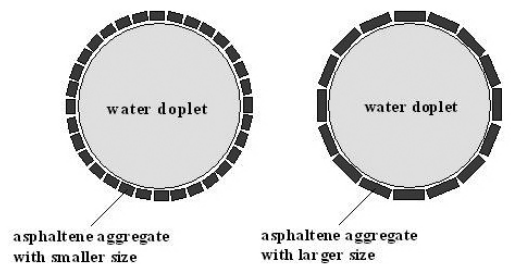

Figure 3S. Voids generated by asphaltene adsorption at the water droplet surface. More voids are generated from small-sized asphaltene aggregates

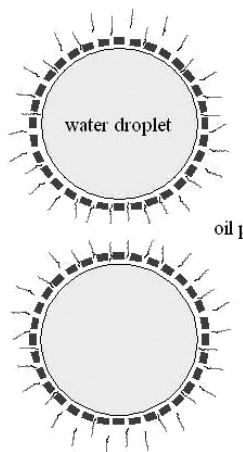

(a)

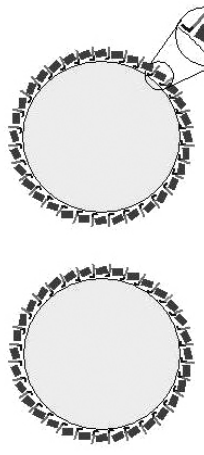

(b)

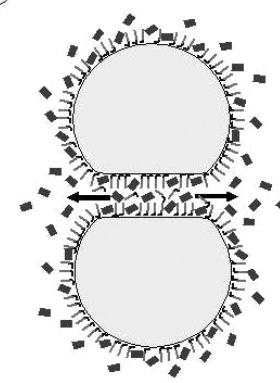

(c)

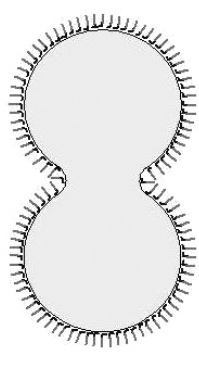

(d)

Figure 4S. The demulsification mechanism of the water-in-oil emulsions: (a) the demulsifier macromolecule crosses the voids between the asphaltene aggregates; (b) the demulsifier macromolecules start adsorbing at interface and counteracting the interaction between the asphaltene aggregates and the water molecules; (c) the asphaltene aggregates displace from the water droplet surface and the Maragoni-Gibbs effects are canceled out; (d) the water droplets coalesce 